\title{
Torque Control System for Diesel Engine
}

\author{
Rajesh H, Arihant U \\ Department of Mechanical Engineering, Sri Venkateswara College Of Engineering, Sriperumbudur, India.
}

\begin{abstract}
This paper presents an idea on torque control system for variable speed diesel engine. A dynamometer assembly is designed to measure the frictional torque on the disc and hence the engine torque. The resistance or frictional torque offered by the dynamometer will vary with time in a desired manner. A transducer is used to measure the torque or force which is the output from dynamometer and is of electromechanical type. The load acting on the transducer creates bending in the sides and a strain gauge has been used to sense the strain. The output of the strain bridge is proportional to the load applied and hence the transducer will give an electrical output proportional to the force. Thus the output of the measuring system will be an emf. The emf signal is proportional to the load torque. However a calibration graph would be necessary to relate the emf output to the load torque.
\end{abstract}

Keywords - Diesel engine, Dynamometer assembly, Emf signal- load torque, Transducer, Strain gauge,

\section{INTRODUCTION}

The experimental work on these engines has been conducted from no load to full load at constant speeds. On these engines, no facilities exist for a continuous variation of load torque and speed. In case of automobile engines depending upon the road conditions and road speed, the engine speed and torque will vary. The road speeds and tractive resistances faced by the vehicle are converted to engine speeds and engine brake torque. Variation of road speed and tractive resistance over a period of time, thus become a variation of engine speed and torque. This setup facilitates varying the load torque representing the variations of the driving cycles, on the test bed.

\section{COMPONENTS}

The components used in setup are disc type dynamometer, torque and speed transducers, stepper motors. The torque sensor is a U- type beam with strain gauges bonded on it. The engine torque creates bending and consequent strain on the gauges. The gauges form a Wheatstone bridge circuit. The output from the bridge is an emf signal proportional to the torque. The speed is measured by directly connecting a tachgenerator, which is a small dc dynamo. The output of the tachgenerator is an electrical emf which is proportional to the engine torque. By applying brakes on the disc of the dynamometer, the braking torque can be varied and hence the load torque also varies respectively. Therfore engine torque can be controlled to the desired value as per the requirement through the braking system.

\section{SPRING ARRANGEMENT}

It starts with a stepper motor receiving the input from the suitably fabricated electronic system and gives the desired turning moment to the sleeve. As the sleeve rotates, it results in the screw moving axially without rotation. The screw does not rotate as it is held in position by the lock screw. As a result of which the screw arrangement moves forward or backward depending upon the rotation given to it by the stepper motor through the sleeve. The head of the screw mechanism fits into the plunger. So as the screw mechanism moves forward, the plunger also moves forward through the sleeve. The cavity inside the sleeve is incorporated with Belleville springs, ten to be precise. As the ram moves forward the plunger compresses the Belleville springs and moves forward against the spring force. The other end of the ram is attached to the brake shoe and hence the brake shoes are pressed against the disc of the dynamometer. Hence brakes are applied. When the brakes are to be released the stepper motor rotates in the opposite direction and spring force helps in bringing the screw back to its original position and there will be no contact between brake shoe and disc. Hence the application of brake is stopped now. 


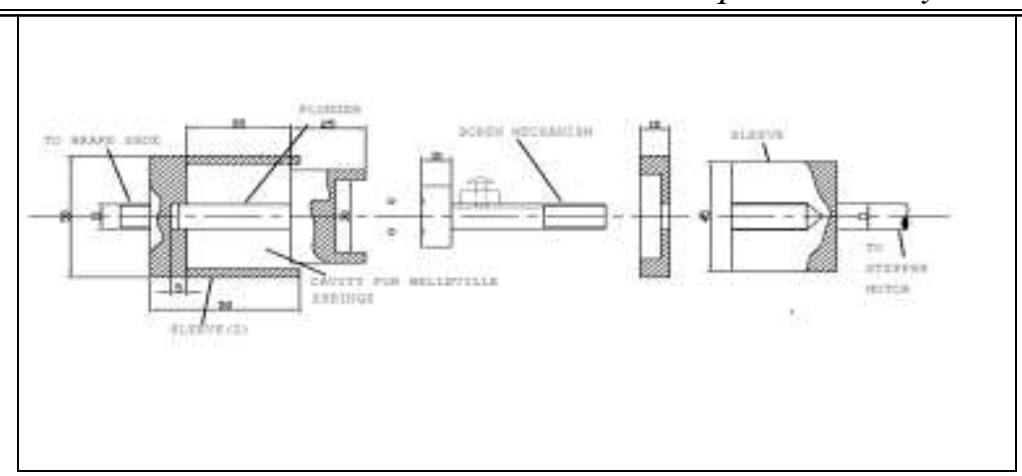

Fig 1: Exploded View Of Screw Arrangement

\section{TORQUE CONTROL SYSTEM}

Here torque is applied by means of a screw and nut arrangement. The nut would be turned by the stepper motor and would move the screw back and forth. The screw would control the pressure applied on the brake pads through a set of disc springs (Belleville type). Thus advancing the screw will increase the brake torque and vice versa. The applied torque is sensed using a strain gauge mounted in $\mathrm{U}$ beam. Torque Indicator is a strain gauge signal conditioner and amplifier used to measure Torque due to load applied on the engine. The strain gauge is bonded on the Specimen and is connected in the form of Wheatstone bridge. The Torque measuring setup is a complete system which can be used to conduct measurement tensional load applied on the engine. The Torque indicator is provided with zero balancing facility through adjustable potentiometer. The system operates on $230 \mathrm{~V}$ Ac supply. Digital strain indicator is given the output from the Wheatstone bridge to measure the micro strain. The instrument comprises of inbuilt power supply for self and also for the strain gauge excitation, strain gauge signal conditioner and amplifier. The main features of the strain indicator are front panel strain gauge Bridge balancing with the help of potentiometer. The whole system is self-contained with all accessories included. The instrument is enclosed in a tapered fiber glass box.

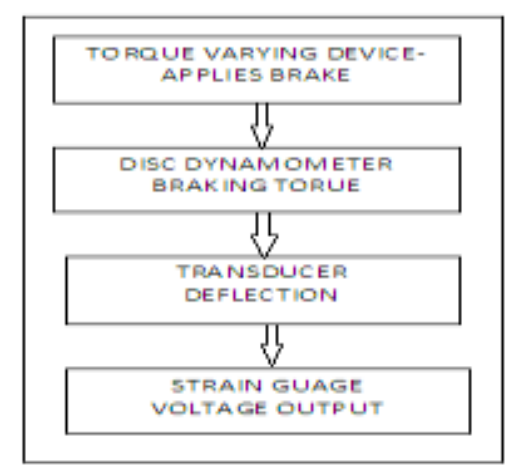

Fig 2: Block Diagram Showing Torque Control Process

\section{RESULTS}

We have tested that it is possible for us to continuously vary the speed and load torque in the ranges of speed: (800-3000) rpm and load torque: (0-16) Nm. The calibration graph for torque of the engine is also drawn.

Table 1: Values between Meter Reading \& Dynamometer Torque.

\begin{tabular}{|c|c|c|}
\hline SLNo & STRAIN METER READING & DYANAMOMETER TORQUE \\
\hline 1 & 3.8 & 4.41 \\
\hline 2 & 7.5 & 8.83 \\
\hline 3 & 11.4 & 13.25 \\
\hline 4 & 13.2 & 15.45 \\
\hline 5 & 18 & 22.07 \\
\hline 6 & 22 & 26.5 \\
\hline 7 & 25.6 & 30.9 \\
\hline 8 & 29.4 & 35.3 \\
\hline
\end{tabular}




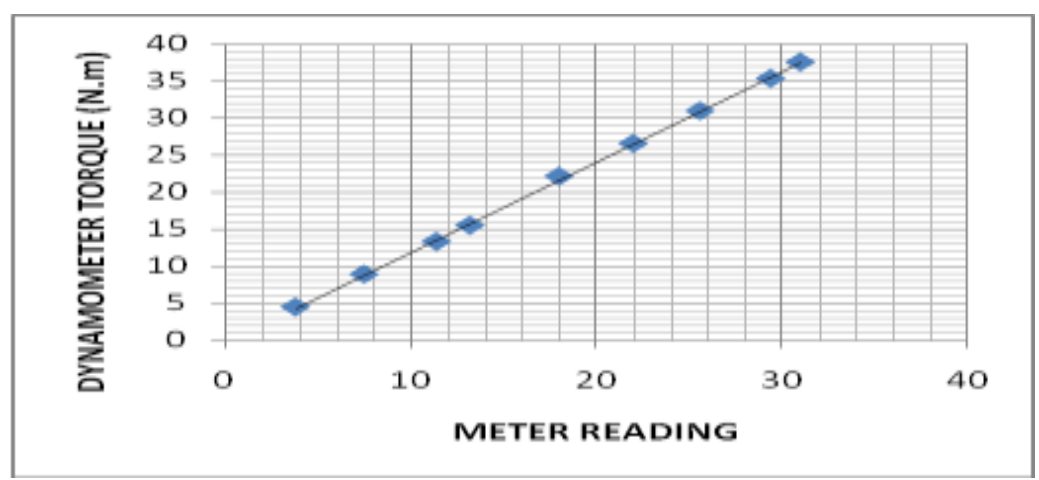

Fig 3: Graph between Meter Reading and Dynamometer Reading

\section{CONCLUSION}

The Torque Control System which we designed is tested for its consistency. Further, the electronic control unit will be developed for automatic torque control of the engine.

\section{ACKNOWLEDGEMENTS}

We would like to thank our guide, Dr.T.V.Balasubramanian, Visiting Professor, Department of Mechanical Engineering, Sri Venkateswara College of Engineering, Sriperumbudur, for all his time and efforts in guiding us through the entire process and for his valuable expertise and inputs for making this work success.

\section{REFERENCES}

[1] Shigley J.E and Mischke C. R., "Mechanical Engineering Design”, Sixth Edition, Tata McGraw-Hill , 2003.

[2] Sundararajamoorthy T. V, Shanmugam .N, "Machine Design", Anuradha Publications, Chennai, 2003..

[3] Maitra G.M., Prasad L.V., "Hand book of Mechanical Design”, II Edition, Tata McGraw-Hill, 1985.

[4] Bhandari, V.B., "Design of Machine Elements", Tata McGraw-Hill Publishing Company Ltd., 1994.

[5] Ugural A.C, "Mechanical Design, An Integrated Approach", McGraw-Hill, 2003. 